\title{
The role of the speciality tutor in the training of junior doctors in psychiatry
}

\author{
Patricia Hughes
}

\begin{abstract}
"The Speciality Tutor is a psychiatrist working in the fields of child and adolescent psychiatry, psychotherapy, forensic psychiatry, learning disability, psychogeriatrics, or the dependencies (drugs and alcohol), who is regarded as the tutor for the organisation of training in that speciality in the Region. There is one tutor for each Region." (Royal College of Psychiatrists, 1996)
\end{abstract}

The speciality tutor is recognised but not appointed by the College. He or she may be appointed by the University, the Regional Postgraduate Education Committee, or by a local committee, for example, the local Division of Psychiatry. The appointment, however, must have the agreement of colleagues (Royal College of Psychiatrists, 1996).

The speciality tutor should be distinguished from the clinical tutors in each district who have overall responsibility for senior house officer (pre-Calman SHO and registrar) training in psychiatry, and from the Programme Director (pre-Calman, the Organiser of Higher Specialist Training) who is responsible for the training scheme for post-membership specialist registrars (previously senior registrars) intending to become consultants in the speciality concerned.

The speciality tutor's remit is to be the regional "organiser of training in the speciality". As the programme director is responsible for the training of post-membership specialist registrars, then the main part of the work of the speciality tutor will be for premembership trainees. This remit is rather non-specific and is one of those tasks which might potentially be a full-time job, or might be merely nominal. The College document on College recognition of tutors (1996) indicates that it is desirable for the tutor to have a session per week and some financial remuneration for the work, but in reality most tutors are likely to be doing the work on top of their usual clinical, teaching and administrative work-load. Any suggestion made about the role of the speciality tutor must therefore be feasible for a busy clinician.
Although the College publishes a list of tutors and speciality tutors across the country, many clinical tutors are uncertain not only about the role of the speciality tutor, but about whether or not they even exist in some Regions. Recent discussion at the Annual Conference of Clinical Tutors in Psychiatry revealed that some clinical tutors do not know who their Regional speciality tutors are. This suggests that there is widespread uncertainty about the responsibilities of speciality tutors.

It would be useful to have a framework to guide the work of the speciality tutor, so that both they and the clinical tutors can use their time and expertise most effectively. This is a proposed outline of how the work of the speciality tutor might be organised.

(1) Identify learning objectives for the trainees. These may be conveniently considered as knowledge, skills and attitude objectives. They should cover the learning that the trainees should get pre-membership in the speciality to equip them both for the membership examination and, more importantly, to take up a post as a specialist registrar either in general adult psychiatry or in one of the specialities.

Giving learning objectives is one good way to communicate with trainees. The more detailed the learning objectives, the more clarity there will be for the trainees and their trainers about what is expected of them. A longer list may not mean that more learning is being asked, but rather that everyone is clear about precisely what that learning should be.

The learning objectives must be congruent with the College curriculum for the membership exam. They must also be agreed with the clinical tutors lest the specialist's enthusiasm for the speciality leads to unrealistic expectations of trainees and trainers.

(2) Identify learning opportunities for trainees in the Region. This has been outlined in the 
Court of Electors statement on approval of training schemes for general professional training for the MRCPsych examination, and includes:

- regular supervison by consultant and specialist registrar

- ward rounds (including presenting)

- case conferences (including presenting)

- learning interviewing skills

- journal clubs

- systematic lectures and seminars

- teaching in related subjects (i.e. from other professionals including occupational therapists, social workers, etc.)

- peripatetic teaching for isolated hospitals, or opportunities for trainee to visit centre

- experience of administration and contact with hospital managers.

In addition, the local University teaching hospitals should offer:

- day or half-day release courses

- specialised clinical supervision (e.g. in psychotherapy)

- supervision of research

- regular meetings with local psychiatric tutors

- teachers to serve on selection committees for trainees

- teachers who will visit local schemes on a regular basis for teaching.

Psychiatric hospitals or mental health units which train junior doctors should provide:

- library facilities

- reasonable teaching facilities

- adequate offices.

(3) Explicitly match learning objectives to training opportunities, detailing what is best learned where. For example, the knowledge objective "outline the classification of disorders associated with the use and abuse of alcohol" may be best learned on the Regional MRCPsych course, and from books and journals. The skill objective "demonstrate that you can identify and treat symptoms of acute alcohol withdrawal" may be best learned in A\&E, in the acute medical ward, in the psychiatric admission ward, from supervision from the consultant, and to an extent from the membership course.

(4) Ensure that trainees and educational supervisors have a written list of the learning objectives and find them feasible. As most trainees will not have the opportunity to work in specialist posts in every speciality, there is a case for the log book scheme to monitor core clinical experience and clinical teaching.

(5) Negotiate course content with course organisers (MRCPsych), so that the necessary learning for the exam is covered in the course. The publication of the College Curricula for the MRCPsych examinations (Royal College of Psychiatrists, 1994) has facilitated this for tutors. The speciality tutor is well placed to advise about further reading and references for trainees.

It is simply not feasible for the speciality tutor who does not have designated time to ensure that library facilities are adequate in all districts throughout the Region. Nor can the tutor monitor the content of journal clubs in all districts. It is, however, possible to check that a central resource, such as a university library, is adequate for the speciality, and that the speciality is represented in a Regional journal club. This leads on to the very necessary sixth step.

(6) Organise regular meetings, perhaps once a term or twice a year, for those involved in speciality training in the Region, such as speciality educational supervisors for audit of training in the speciality. These educational supervisors are in a position to collaborate with the clinical tutor in the district to ensure representation of their speciality in district journal clubs and local hospital libraries.

(7) Attend Regional Postgraduate Education meetings and Regional Tutors meetings where issues relating to senior house officer training are discussed and organised.

(8) Organise a system of feedback from trainees to monitor the delivery of training. Again, the log book, with explicit feedback from trainees about the quality of the teaching and supervision in individual posts and districts, may be a useful means of communication. Meeting with trainees as a group may be desirable, but unless they can be captured at the Regional MRCPsych course, poor attendance may be a problem.

(9) Give advice about higher training in the speciality to SHOs seeking training posts at specialist registrar level.

\section{Conclusion}

In many Regions this scheme may be seen as redundant, since the clinical tutors and course organiser already include speciality training in the overall organisation of SHO training. 
However, some clinical tutors may find it useful to delegate appropriate responsibility to the speciality tutors who will have a greater knowledge and experience of the speciality. The implementation of a scheme like the one outlined above would involve some work to set it up, particularly in the identification of learning objectives, but has potential for providing trainees and trainers with an explicit structure for their educational task during the three years of SHO training.

\section{References}

Royal College of Psychiatrists (1994) The Basic Sclences and Clinical Curricula for the MRCPsych Examinations. London: Royal College of Psychatrists.

- (1996) College Recognition of College Tutors. Speciality Tutors and Course Organisers for General Professional Training. London: Royal College of Psychiatrists.

Patricia Hughes, Senior Lecturer and Consultant in Psychotherapy. St George's Hospital Medical School, London SW17 ORE

\section{Prevention of Anxiety and Depression in Vulnerable Groups}

\section{Joanna Murray}

The scope of this review, commissioned by the Department of Health, is the common mental disorders of anxiety and depression occurring in adults in the community. It considers the possibilities for prevention in primary care. This combination of basic conceptual and research information provides a practical framework of preventive strategies for the primary care team. Social factors in aetiology are examined in detail, and epidemiological data is used to consider vulnerability factors and to identify high risk groups. There is also a thorough review of risk for common mental disorders. Ł7.50, 112pp., 1995, ISBN 0902241877

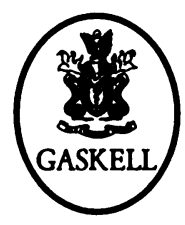

Gaskell books are available from good bookshops and from the Publications

Department, Royal College of Psychiatrists, 17 Belgrave Square, London

SW1X 8PG (Tel. $+44(0) 171235$ 2351, extension 146).

The latest information on College publications is available on the INTERNET at: http://www.demon.co.uk/rcpsych/ 